\title{
An Empirical Case Study of Project-based Innovation Practice for Undergraduate Students
}

\author{
Bingyi $\mathrm{Hu}^{1, *}$, Shuchun $\mathrm{Li}^{2}$, Xiaorui $\mathrm{Shi}^{3}$ \\ ${ }^{1}$ School of Computer and Information Technology, Beijing Jiaotong University (Beijing) \\ ${ }^{2}$ Beijing Jiaotong University (Weihai) \\ ${ }^{3}$ Beijing Jiaotong University (Weihai) \\ *Corresponding author. Email: hby@bjtu.edu.cn
}

\begin{abstract}
Student innovation projects are much favored by students who have innovation interests and abilities in China. This article proposes a research-oriented support model which focuses on: the importance of cooperation in college students' innovation practice, developing work packages, time lines and milestones, producing on-going record-based process control mechanisms, and improving problem solving skills. Through an experimental design, a test group was developed to trial the new innovation process model, whilst a control group used the traditional innovation project support process. This paper reviews the experiment and provides recommendations and effective methods for the smooth progress of undergraduate innovation projects on the basis of research and innovative ability training.
\end{abstract}

Keywords: Student innovation practice, Ability training, Cooperation, Project split.

\section{INTRODUCTION}

Entrepreneurship, innovation and creativity are three pillars identified globally as essential for the ongoing sustainable development of economies in the future. The European Commission suggests education as a prerequisite for creating European innovation space leading to a conclusion that governments need to promote creativity and innovation throughout the education cycle [1].

Innovation is the key to a country's competitiveness and within China has received unprecedented attention, where it is felt that innovation is key to the future of the motherland [2]. In order to ensure that graduates have innovative skills to meet this challenge, it is necessary to use innovative engineering to improve students' ability.

Within the context of "mass entrepreneurship and innovation [3]", most universities in China offer innovation credits that can be obtained through innovation courses and participating in innovation practice [3]. These courses are designed to address the need to cultivate future talents, and the opportunity to 'practice' innovation is a significant way to increase innovative behaviors [4].
Globally, students appreciate the opportunity to develop their entrepreneurial and innovative skills, particularly through practical application. It enables students to embrace independent working and add to their researching skills, through the application of theory to practice. However, there are problems faced by students and staff in ensuring this type of learning experience [5].

Although a series of procedure controls such as proposal evaluation, mid-term check, and final defense are applied to prevent students from going off-course, However, this method does not train students to consider the planning, documentation, problem solving and co-operative working that is required for a successful innovation project. This paper therefore develops and tests procedures currently used as part of the Masters Research programme, providing a model for innovative practice and pre-Masters training at undergraduate level.

\section{METHODOLOGY}

The research design has been based on two principles. The first develops a model for innovative practice and pre-master's training. The second uses an experimental design framework [6], were a control group, using the current procedures for innovative 
practice, and an experimental group who followed the new model of procedures.

\section{PROCEDURES MODEL}

Traditional innovation projects at undergraduate level follow the process controls of proposal, mid-term check and final defence. For most students the challenge is how to move their project from a proposal to implementation and through to completion. When considering the process of innovation projects, there are similarities in procedure to that followed by master's students embarking on their research. Although similarities exist, there are differences. The main difference is that the undergraduate innovation project is conducted through team work, rather than individually based, which needs to be accounted for in the model developed. There is also an opportunity to address some of the challenges that exist in the current master's research process.

In this working model, team work enables cooperation between team members providing increased knowledge for the team to draw on, and additional resources to ensure that the project can be finished on time. The team compensates for the shortage of knowledge and time. Each team has an advisor from the faculty staff who help to facilitate the various stages of the project.

\subsection{Team Formation and Cooperation}

Cooperation activities play an important role in innovation, and team working is considered to be an effective means for industrial organizations to support complex research, development and innovation [7]. Cooperation provides opportunities for complementary technical resources (such as skill sharing), enabling innovation projects to be completed in a timely fashion.

Complimentary skills are also a requirement of good team co-operation [8]. Between the team members there needs to be the ability to develop critical literature reviews, basic theoretical concepts, the ability to think creatively and critically, and the ability to write reports and summarize actions. Member's ability is another criterion of good cooperation.

a) Literature reviews are the first step in any research project, with the essential role of establishing what has already been completed within the field of study.

b) Basic theory is the fundamental of the innovation practice. It is the necessary condition to analysis and resolve problems.

c) Critically creative ability enables the process of testing and adjusting the project perimeters. d) The abilities of reporting and summarizing are the guarantee to ensure correct data and results, laying the foundation for analysis.

The combination of skills and abilities within the team are critical to enable the project to move forward smoothly, however the common problems that occur within teams include:

a) Students tend to form teams composed of like-minded friends, thereby reducing the chances of each team member contributing different skills.

b) Social loafing within the teams occurs when 1 or more students within the team do not engage in the project, creating disharmony within the team [9].

It is essential therefore that students understand the importance of the various skills that each brings to the team, rather than relying on working in a team with friends.

\subsection{Make Things Simple}

Once the team is formed the initial starting point is enabling the students to take a complex project and break it down into 'work packages' that can be allocated to members of the team. Each package should contain a specific task that needs to be completed [10].

An important role for the advisors at this point in the planning process is to be aware of the students' knowledge levels. Whilst it is necessary to for students to gain new knowledge as part of the learning process, this should be within acceptable boundaries of around $20 \%$.

However, undergraduate students lack of knowledge and understanding create difficulties in moving from the macro scale of the project to the micro level of project planning, which helps to make the project simpler to plan and co-ordinate. The consequence of not being able to develop the work packages often brings the project to a standstill resulting in project failure. It is at this point that assistance from the advisor is crucial, to ensure project success and the skills development of the students.

The keyword here is to "assist" the team in completing this task. It is important that students actually identify and schedule the work packages themselves so that the appropriate depth of learning can take place. The following recommendations can help the advisor "assist" rather than "do" the task.

a) To help them analyse the requirement of the innovation project and clarify what is known and what is, as yet, unknown. known parts and unknown parts. 
b) To guide students in finding the basic theories needed to relate to the areas of the project that are currently unknown. This is also an area where students perceive a difference between the more systematic structuring of course learning, and the type of learning that takes place when engaging in project work.

c) Advisors should pay attention to students' independent working ability and team spirit.

d) It is strongly advised that the team does not become dependent on the advisor, as this will take away the creative and innovative outcomes that project work is designed to enhance.

\subsection{Quantity Increase: from Simple to Complex}

Once the work packages have been created, the team needs to schedule the tasks and create a timeline, with appropriate milestones. This activity requires the students to change focus from the micro planning stage to the macro planning view. Students need to logically consider the relationships between the different work packages to ensure a rational implementation plan for the project. The sequencing should also consider students' knowledge level, easier tasks that can be completed with current knowledge build confidence to enable more difficult tasks to be tackled.

On the time line, the students need to identify specific milestones that will help them track the progress of the project and be able to make timely interventions if required. The milestones need to be measurable.

\subsection{Qualitative Leap: Complex to Simple}

Through the stages outlined above, the students will have gained basic theories and skills that will enable them to face the challenges of implementation.

Advisors should introduce methods of resolving problems, particularly on how to analyse the problem so that the solution can be developed, thus keeping the project moving forward. The ability to analyse and solve problems is the fundamental essence of innovation projects. The students learn that complex things can become simple to solve if the correct methods are used to analyse.

\section{MANAGEMENT}

Although the existing management of innovation practice is effective and successful, for example, the three phases of proposal evaluation, mid-term check and final defence have controlled the key of practice procedure, the model based on master's research enables students to accurately plan their project, providing guidance on how to develop the proposal into an implementation plan. However, one of the areas not addressed is that of managing the project, once implementation starts. For this, an additional element from Part 7 of ISO9000 [11], provides a way of utilizing documentation that helps the project team keep track of the implementation phase, contributes to team cooperation, team problem-solving, and sustainability of resource requirement.

\subsection{Mechanism of Procedure Control Based on Documents and Records}

In order to successfully manage the project through the implementation stage, innovation teams should be encouraged to complete documentation, kept in real time, throughout the implementation phase. The initial phase of the project planning, starts this process with the development of work packages, timelines and milestones. These documents enable the team to identify responsibilities and avoid misunderstandings around the project requirements. Ongoing project documentation provides the following resources for the team:

a) When problem solving, tracing back a problem can help identify the solution.

b) Track progress of the project, enabling measurably conformance to the milestones.

c) Provides a way to allocate and monitor the use of resources, enabling the project to keep to the budget initially agreed, and improving project sustainability.

\subsection{Project Contracts}

Innovation projects are a contract between the university and the student team. To increase student awareness of responsibilities and obligations in terms of considered use of human resources, materials and financial resources a project contract should be signed. The project documentation will then provide the record required to ensure the contract is meet and that resources are used responsibly.

\section{CASE STUDY}

Between 2016 and 2021, there have been 21 groups with 63 students engaged in the innovation projects, which the authors have taken part in. to test the pretraining master's model a test group and a control groups were identified (See Table 1). The control group fulfilled their innovation projects according to the traditional support model, whilst the test group were offered the enhanced support model. 
The results indicate that the test group performs better with $100 \%$ pass rate and the development of wellplanned projects at the proposal stage. However, the test group spent more time on the projects than the normal group, which meet for 1 hour per week.

However, this additional time spent by the test group, resulted in the research becoming part of their normal activities, rather than leaving the implementation and having to complete a fast finish. The control group tended to spend a lot more time on the project as it neared the completion date.
On the view of procedure control, the continuing working and recording ensures a clear research path. The documentation provided a way to trace back problems and resolve them at source. The documentation also enabled the projects to be more accurately monitored against the milestones set by the test teams. The control teams' projects were monitored at two fixed points, the mid-term review and the final defence.

Table 1. The evaluation of activities

\begin{tabular}{|c|c|c|}
\hline Contents of evaluation & Test group & Normal (Autonomous) group \\
\hline Cases \& students & 5 cases, 15 students & 16 cases, 48 students \\
\hline \multirow[b]{2}{*}{ Proposal phase } & Meeting 2-3hours/week & Meeting 1hour/week \\
\hline & $\begin{array}{c}\text { Well planned, tasks and problem are } \\
\text { clarified }\end{array}$ & Rough plan, understanding main tasks \\
\hline \multirow{2}{*}{ Mid-term } & $\begin{array}{c}\text { 1-2hours/week } \\
\text { Average: } 1.5 \text { hours/week }\end{array}$ & $\begin{array}{c}\text { Sometimes 1-4hours/week, sometimes idle, } \\
\text { Average: <0.5hours/week }\end{array}$ \\
\hline & $\begin{array}{l}100 \% \text { (5cases) Well-organized, } \\
\text { Completed planned tasks }\end{array}$ & $\begin{array}{l}25 \% \text { ( } 4 \text { cases) well-organized, } \\
37.5 \% \text { ( } 6 \text { cases) completed planned tasks }\end{array}$ \\
\hline \multirow[b]{2}{*}{ Final defense } & 1-2hours/work for last month & 2-4hours/week for last month \\
\hline & $100 \%$ ( 5 cases) Goals completed & $\begin{array}{c}50 \% \text { ( } 8 \text { cases) Goals completed, } 31.3 \% \text { ( } 5 \text { cases) } \\
\text { main body completed, } 28.7 \% \text { ( } 3 \text { cases) partly } \\
\text { completed }\end{array}$ \\
\hline Future research & $80 \%$ (12 of 15 ) well presentation & $35.4 \%$ (17 of 48 ) well presentation \\
\hline
\end{tabular}

\section{CONCLUSION}

There are several advantages and disadvantages designing student's innovation projects as pretraining for master degree research.

The first advantage is improvement of researching methods. The students have learned how to make plan, develop a complex project into simple tasks, and experience high levels of achievement through solving complex problems.

The second one is enhancement of skills. The skills consist of literature retrieval according to the requirements, experimental skill, making records of experiment and providing timely information.

The third one is improving cooperating ability. Although independent working ability is important to master degree students, the ability of cooperation is necessary to support their research. This is particularly important as much research is cross-disciplinary at master's level.

The disadvantage is that it takes more effort for students and advisors. Students not only need to finish a project, but also need to learn a lot of methods and skills, as well as project management. For the advisors there are resource implications in terms of time that is required to advise the student project teams.

\section{ACKNOWLEDGMENTS}

This work was carried out in Beijing Jiaotong University, (Beijing and Weihai campus), we gratefully acknowledge the invaluable contribution of Tingting Zhou, in supporting our research. We deeply grateful to adviser, Christine Mortimer from Lancaster University with management experience, for her support and guidance in modifying and polishing the language, making the article more academic and professional.

\section{REFERENCES}

[1] Li, Keqiang, government working report, 2020.

[2] Zuljan. V, Milena, Vogrinc, Janez, Facilitating effective student learning through teacher research and innovation, Univerza. v Ljubljani, Pedagoška fakulteta, 2010, http://doi.org/978-961-253-051-8

[3] Wang. L, Wang. C. Y, and Nian. D. J et al, Study on Cultivation of Innovation and Practice Ability 
for College Students Based on Scientific and Technological Competition, in: Advanced Materials Research, vol. 271-273,2011, pp. 17641767.

DOI: https://doi.org/10.4028/www.scientific.net/AMR.2 71-273.1764

[4] Trina. C. K, Seepersad. C.C, Hölttä-Otto.K, Williams. P. T, Young. A.P, Bhowmick. S, McCarthy. M. A, The Effects of the Undergraduate Curriculum and Individual Differences on Student Innovation Capabilities, in :Proceeding of the ASME 2014 International Design Engineering Technical Conferences and Computers and Information in Engineering Conference, Buffalo, New

York,2014,3(16),https://doi.org/10.1115/DETC201 4-35540

[5] S. J. HARKEMA, H. SCHOUT, Incorporating Student-Centred Learning in Innovation and Entrepreneurship Education, in: European Journal of Education, vol. 131, no. 4, 1981, pp. 52-71. DOI: https://doi.org/10.1007/BFb0025774।

[6] Hsiao. H.C, Chen. S. C, Chang. J.C, Chou. C.M, Shen. C.H, Factors that influence school organizational innovation in technical institutes and universities, World Transactions on Engineering and Technology Education,7(1)2009

[7] Saunders, M., Lewis, P, \& Thornhill, A. Research methods for business students (Seventh ed.). 2016, New York: Pearson Education.

[8] P.D. Faria, F. Lima, R. Santos, Cooperation in innovation activities: The importance of partners, in: Research Policy, vol 39, no.8, 2010, pp. 10821092.

DOI: https://doi.org/10.1016/j.respol.2010.05.003

[9] Haas, M and Mortensen, M. The Secrets of Great Teamwork, in: Harvard Business Review, 2016, pp. 70-76. DOI: https://hbr.org/2016/06/the-secrets-ofgreat-teamwork

[10] Jassawalla, A, Hemant S, and Avinash S1. "Students' perceptions of social loafing: Its antecedents and consequences in undergraduate business classroom teams." Academy of Management Learning \& Education 8.1 (2009): 42-54.

[11] Prince 2: Managing Successful Projects with PRINCE2, 2009, UK: The Stationary office (UK Government publication).

[12] ISO 9000: Quality management systems. 